\title{
Mirella Romero Recio y Guadalupe Soria Tomás (eds.), El almacén de la Historia. Reflexiones historiográficas. Madrid: Biblioteca Nueva, 2016, 287 págs.
}

Todo aquel que pretenda indagar en el estudio de la Historia debe tener en cuenta que las fuentes documentales que se encuentre no le remitirán con exactitud a los hechos, sino que la forma de contarlos estará siempre influenciada por el contexto histórico, social, cultural, ideológico y/o incluso personal que rodea al historiador que redactó el documento, o incluso al traductor de los documentos (si es una traducción lo que se tiene a mano). A todos aquellos, profesionales o aficionados, interesados en investigar cómo ha llegado a nosotros la Historia, va recomendado este libro. Se trata de una obra colectiva de catorce capítulos que estudia la historiografía de épocas y ámbitos muy diversos y que forma parte del proyecto El Almacén de la Historia.

Este volumen ha sido editado por las doctoras Mirella Romero Recio y Guadalupe Soria Tomás, profesoras de Historia Antigua y Literatura Española, respectivamente, en la Universidad Carlos III de Madrid. Los enfoques que proporcionan ambas especialistas, el histórico y el literario, son los que hacen posible un estudio completo sobre las causas, estructura e ideas transmitidas en cada historiografía, sobre las diferentes interpretaciones que se han realizado de los hechos del pasado, atendiendo a los contextos que se vivían en cada época.

Además del trabajo de las editoras, la obra cuenta en cada uno de los catorce capítulos con la aportación de Ana Rodríguez Mayorgas (UCM), Antonio Gonzales (Université de Franche-Comté), Beatrice Cacciotti (Università degli Studi di Roma "Tor Vergata"), María Jesús Fuente (UC3M), Carlos Estepa Díez (CSIC-Instituto de Historia), Miguel Ángel Marzal (UC3M), Laura Branciforte (UC3M), Ignacio Peiró Martín (Universidad de Zaragoza), José Manuel Querol Sanz (UC3M), Alfredo Alvar Ezquerra (CSIC-RAH), Francisco García Jurado (UCM) y Marie Salgues (Université Paris 8 CREC).

Todo se centra, pues, en analizar y estudiar la historiografía siempre desde el contexto histórico en el que se escribe. Esto ya nos lo ilustra el prólogo, en el que las editoras nos aconsejan "leer entre líneas" y "tener siempre en cuenta el contexto histórico en el que se han generado las obras" (p.13). Este es el punto en el que convergen los catorce artículos tan dispares que componen la obra.

El propio título del libro, El almacén de la Historia. Reflexiones historiográficas, también es bastante ilustrativo y nos adelanta qué es lo que nos vamos a encontrar pues, como afirman las propias editoras: "la Historia se almacena pero se constituye, asimismo, en un gran almacén que no deja de gestar y difundir las interpretaciones sobre las que reflexionar" (p. 13). Así, con esta acertada metáfora, se define a la perfección el proyecto en el que se basa el libro, donde se buscan, no solo los volúmenes historiográficos claves para entender la Historia, sino el contexto en el que estos fueron redactados, a fin de comprender por qué se ha interpretado la Historia de una forma $u$ otra en un momento y una obra determinados. 
Tras el prólogo, inaugura el libro el capítulo de Mirella Romero Recio, que nos traza un recorrido a lo largo de la historiografía de la Antigüedad en España. En él podemos observar cómo en la España del siglo XVIII existía ya un estudio interesado de la Historia de la Antigüedad que únicamente se centraba en los matices que pudieran servir para ensalzar la historia de la nación. Es por esto por lo que, en un principio, solo interesaba estudiar la Historia de Roma, al considerarla antepasado directo de España. Posteriormente, el trabajo de investigación histórica fue quedando en manos de las universidades (como la Universidad Central de Madrid), por lo que ya se podía conocer también algo de la Historia de Grecia, aunque siempre recurriendo a traducciones de obras extranjeras. En el siglo XIX, sobre todo con la famosa Ley Moyano, la universidad española comenzó a avanzar en la Historia del Mundo Antiguo, y se promocionó cada vez más la Historia de España como materia. Finalmente, a finales del siglo XIX y principios del XX, la arqueología revolucionó el estudio de la Historia y motivó los viajes de estudio a los yacimientos, para conocer de primera mano la cultura material que se conserva.

Muy relacionado con el estudio universitario de la Historia en España está también el capítulo de Ana Rodríguez Mayorgas, que se centra, en concreto, en los estudios y publicaciones de Juan de la Gloria, catedrático de Historia Universal en la Universidad de Granada. Tras unos breves apuntes biográficos, la autora nos presenta la obra de Juan de la Gloria, destinada principalmente a que los universitarios tuvieran la Geografía e Historia Universal sintetizada mediante manuales y atlas. Se nos presenta como un historiador marcado por su contexto histórico y personal, pues, como creyente que era, Dios estaba presente en su obra como creador de la naturaleza humana, aunque no considera que interviniera en el surgimiento y la evolución de los pueblos y las culturas antiguas. También se nos presentan como base de la obra de Juan de la Gloria los conceptos "raza", "cultura" y "nación", considerando a la raza blanca como la cultura superior, a la negra como la más atrasada y a la asiática como incapaz de innovar, todo ello entendido dentro del contexto colonial del siglo XIX. En cuanto a naciones y culturas, sigue la teoría de Montesquieu que clasifica en "grados de civilización" a los pueblos según el clima. En definitiva, Rodríguez Mayorgas nos ilustra con un ejemplo claro de cómo el contexto en el que se vive condiciona el estudio de la Historia.

Sin duda, el contexto más común en el estudio de la Historia es que esta se encuentre al servicio del poder, algo con lo que nos ilustra Antonio Gonzales en su capítulo dedicado, concretamente, al Franco Condado, propiedad primero española, en manos de los Austrias, y, posteriormente francesa, que reivindicaba su autonomía a través de la Historia. Esta autonomía la reclamaban, sobre todo, las élites aristocráticas del Franco Condado y la elaboración de una historia del territorio y su pueblo era uno de sus instrumentos claves. Así, de manera similar a Alemania, Francia y otros muchos Estados modernos, defendían su independencia utilizando como argumento un pasado idealizado, difuso e irreal que les hacía descendientes del pueblo de los secuanos. Para ello, emplean las fuentes historiográficas de las que disponen: las romanas. Esta nostalgia e idealización de un pasado glorioso que nunca existió será un uso interesado de la Historia que se realizará no solo en el Franco Condado, sino prácticamente en todos los Estados conocidos hasta nuestros días. 
Pero el estudio de la Historia no es único de los documentos escritos. También es importante el análisis de la cultura material, es decir, de los objetos que se conservan del pasado. En ellos se ha centrado Beatrice Cacciotti en el capítulo que dedica al coleccionismo de antigüedades de Italia y España entre los siglos XVI y XIX. La autora nos hace un recorrido por las principales colecciones conservadas en museos, como la de Isabel de Farnesio o Cristina de Suecia, así como nos explica las motivaciones que llevaron a reunirlas a sus dueños y su posterior musealización. Quiero destacar, además, la inclusión de documentación gráfica en este capítulo, que nos da una información más detallada de la investigación llevada a cabo en el mismo.

Tradicionalmente, casi siempre que se ha investigado cualquier ámbito de la Historia, se ha hablado únicamente de los hombres que han participado de ella, obviando el papel de la mujer en la misma, bien por falta de documentación o bien por el contexto de épocas pasadas. Afortunadamente las investigaciones más recientes nos han descubierto grandes mujeres de la Historia que el tiempo había dejado en el olvido. Una de esas investigaciones es la que se plasma en el capítulo de María Jesús Fuente dedicado a las reinas medievales hispanas en la historiografía de los siglos XVIII al XX. En él se puede observar cómo se analizó a dichas reinas, elogiándose a algunas por sus "virtudes" y criticando a otras por no tenerlas. Lo que es virtuoso y lo que no, así como la recepción de un mensaje idealizado de las reinas medievales en la historiografía del siglo XIX viene dado, sobre todo, por las ideologías católica, liberal y nacionalista propias de la época. Destaca, sobre todo, el retrato de doña Sancha de Castilla que realiza Juan de Mariana, el cual influiría posteriormente en la obra de Enrique Flórez, clave en el capítulo.

De la figura de las reinas, pasamos a la de un rey, en concreto, Alfonso X, analizada en el capítulo escrito por Carlos Estepa Díez. En él se analiza cómo se ha estudiado al monarca como legislador, historiador y astrólogo. Se puede observar cómo este rey ha sido descrito de diversas maneras por la Historia, desde la visión negativa del padre Juan de Mariana, que criticaba que su dedicación a la astrología le hizo fracasar en el terreno político, a la edición crítica de su Estoria de España, realizada por Ramón Menéndez Pidal, centrada en su faceta de historiador. Destaca cómo del monarca se han intentado maquillar u ocultar siempre sus escritos sobre astrología, denostada en tiempos posteriores, llegando incluso a sustituirse la palabra "astrología" por "astronomía" para evitar su mala fama en la edición de los scriptoria del rey publicada por Manuel Rico y Sinobas.

Posteriormente, Miguel Ángel Marzal nos presenta un estudio sobre las repercusiones y aproximaciones historiográficas de las Vísperas Sicilianas en la Península Ibérica. El autor destaca el papel importante que jugaron las efemérides y las crónicas en el tratamiento historiográfico de dicho acontecimiento, así como el del nacionalismo italiano, que lo consideró un precedente de la nación italiana y de su unificación. Relaciona, además, las Vísperas Sicilianas con los sucesos de la Asamblea de Valladolid, ambos ocurridos en 1282 y que las fuentes historiográficas analizan dentro de una misma unidad histórica. 
La mujer vuelve a tener un papel destacado en el artículo de Laura Branciforte, esta vez, ligada a dos eventos destacados de la Historia de España: la Guerra de Independencia y la crisis de 1898. Destaca, sobre todo, el "patriotismo femenino" y la inclusión de mujeres en el estudio historiográfico que se realizó de la Guerra de la Independencia a inicios del siglo XX. La obra fundamental empleada en este capítulo es Las heroínas españolas del conde José de Salazar y Souleret (1901), donde se muestra la heroicidad de cuatro mujeres en el conflicto. El objetivo no es otro que mostrar al pueblo español (hombres y mujeres) unido contra el invasor (la Francia de Napoleón) en una guerra utilizada casi como el "mito fundacional" del nacionalismo español. Se vuelve a idealizar, una vez más, un pasado glorioso e irreal en una época como la de la crisis de 1898, en el que imperaba el pesimismo y se añoraba una utópica Edad de Oro.

De una fase oscura de la Historia de España, como la crisis del 98, el volumen pasa a otra con el capítulo de Ignacio Peiró Martín, que analiza el cambio que supuso en las cátedras de Historia el triunfo del franquismo y el tiempo de la Posguerra. Destaca el uso del término "dioses liberales" de la historiografía española para referirse a aquellos que marcharon al exilio, no por ser mejores que los que se quedaron, sino porque "sus nombres sonaban tan lejanos que lo parecían (dioses)". Era la caída de una forma de ver y estudiar la Historia y la llegada de otra, en una época en la que el miedo y las sospechas hacia el pasado estaban muy presentes.

El punto de vista literario, que hasta ahora ha estado menos presente en la obra que el histórico es el que proporciona José Manuel Querol Sanz cuando nos habla en su capítulo de cómo se ha ido formando la imagen popular del general bizantino Belisario a través de la literatura. La historia ha pintado al general de distintas formas: como virtuoso en los tiempos previos al periodo de revoluciones, como símbolo de la injusticia en el periodo revolucionario e incluso se destaca una imagen didáctica, a través de su hija. Pero, el autor, finalmente asegura que la posmodernidad "ha dejado sin óbolo al ciego Belisario" (p. 209), debido a cómo se han interpretado en la actualidad las virtudes que la literatura anterior le había otorgado.

Pero conocer los testimonios y estudios realizados sobre el pasado no sería posible sin los documentos tangibles que los guardan: los libros. En concreto sobre las obras del Humanismo del siglo XVI y su interés en el siglo XVIII versa el artículo de Alfredo Alvar Ezquerra. En él, se nos relata cómo en el siglo XVIII se despertó el interés por el pensamiento humanista de los autores del siglo XVI e incluso del XVII por parte de los eruditos de la Ilustración española. Esto no fue algo accidental, sino que fue producto de un contexto cultural propicio para ello: el interés de una burguesía potentada, con estudios superiores e interesada en la erudición. Además, como siempre, en todo esto hay un claro trasfondo político, pues algunos de estos Ilustrados buscaban, como Feijoo, configurar una la idea de España, de patria unida, ante el menosprecio de los ilustrados europeos. Alvar Ezquerra centra su estudio también en las bibliotecas de los jesuitas, que poseían muchos de estos volúmenes, y en qué fue de ellas una vez que fueron expulsados de España.

En relación con las expulsiones y los exilios está el siguiente capítulo del libro, que corre a cargo de Francisco García Jurado. El autor se centra en los manuales de literatura griega y latina españoles desde los jesuitas de la segunda mitad del siglo 
XVIII hasta la Segunda República, pasando por el siglo XIX y el reinado de Alfonso XIII. Aquí, se nos advierte de la "doble historia" de los manuales: la que nos narran y en la que se publicaron, entrando una vez más en juego la idea del contexto histórico que modifica en cada momento la forma de contar una misma historia. De hecho, el estudio de la historia de la literatura latina y griega tendrá en España periodos de renovación (como la época de los monarcas ilustrados, como Carlos III, que buscaba llenar el hueco de los jesuitas), y de crisis (como durante el reinado de Fernando VII, en el que primó el inmovilismo). Así, se nos muestra que no solo el estudio de la historia, sino también el de la literatura, está condicionado por el tiempo en el que se realiza y se puede observar a través de sus manuales.

Nos topamos con la historia en prácticamente todos los ámbitos de la vida, algo que también nos demuestra Marie Salgues en su capitulo dedicado al teatro de actualidad militar de la segunda mitad del siglo XIX. La autora pone en común el momento de auge de este tipo de teatro con el de los museos abiertos al público en un punto concreto: eran la composición de un patrimonio colectivo e indivisible que ensalzaba la gloria de la patria y la acercaban al pueblo llano, con intención de crear un sentimiento patrio común. Destaca el papel que juega en todo ello el teatro costumbrista, que nos muestra los principales comportamientos, vestimentas y forma de actuar considerados tradicionales o propios de españoles, creándose así unos parámetros y convenciones que daban la sensación de no cambiar a lo largo del tiempo.

Finalmente, el libro se cierra con el capítulo de Guadalupe Soria Tomás, que nos presenta la manera en la que se trata a la dinastía de los Borbones en el teatro, llegando hasta prácticamente obras recientes como La novia del príncipe de Juan José Alonso Millán, que narra las relaciones amorosas del hoy Felipe VI. Aunque también hay espacio para las piezas dedicadas a la alabanza y encomio de la monarquía (como las loa La joya de la lealtad para el pecho de la ley), destaca el papel de las obras críticas con la misma. El ejemplo destacado en el capítulo es el de Valle-Inclán en su obra Farsa y licencia de la reina castiza, donde, a través de una sátira esperpéntica hacia el reinado de Isabel II, realizaba una crítica a la gestión del monarca de su época, Alfonso XIII.

En definitiva, como ya dije al principio, recomiendo este libro a todo aquel que se pregunte por qué y cómo se ha forjado la Historia que hoy conocemos, la que nos ha llegado a nosotros. Además, a través del descubrimiento de que la Historia que nos ha llegado a través de manuales escolares, obras de teatro o esculturas no es sino una interpretación del pasado acorde al contexto de la época en la que se elaboraron, el lector puede realizar un ejercicio de valoración crítica personal y plantearse hasta qué punto la Historia que conoce o ha estudiado no es sino una nueva interpretación basada en el contexto social, político o personal. En los tiempos que corren, donde aún se altera la historia del pasado con fines políticos, económicos o de algún otro tipo, que la lectura de una obra pueda despertar ese espíritu crítico en un lector es un valor añadido.

Por lo tanto, hay que felicitar a las editoras de este fantástico libro, Mirella Romero Recio y Guadalupe Soria Tomás, así como a todos aquellos que, en los capítulos, han contribuido a entender un poco mejor los cambios que se han producido 
en el estudio de la Historia en los diferentes momentos de esta. A todos ellos mi felicitación y agradecimiento particular por este magnífico libro.

Raúl Muñoz Tirado

Universidad Autónoma de Madrid

raul.munnozt@alumni.uam.es

Fecha de recepción: 20 de agosto de 2018.

Fecha de aceptación: 12 de septiembre de 2018.

Publicación: 31 de diciembre de 2018.

Para citar este artículo: Raúl Muñoz Tirado, "Mirella Romero Recio y Guadalupe Soria Tomás (eds.), El almacén de la Historia. Reflexiones historiográficas. Madrid: Biblioteca Nueva, 2016, 287 págs.”, Historiografías, 16 (julio-diciembre, 2018): 130135. 